\title{
A Water Level Meter Made of Capacitor of Two Pairs
}

\author{
Masaharu Moritsugu ${ }^{a, *}$, Yuhki Kitazono ${ }^{b}$, Huimin Lu$^{a}$ and Seiichi Serikawa ${ }^{a}$ \\ ${ }^{a}$ Kyushu Institute of Technology, 1-1 Sensui-cho, Tobata-ku, Kitakyushu-city, Fukuoka, 804-8550, Japan \\ ${ }^{b}$ Kitakyushu National College of Technology, 5-20-1 Shii, Kokuraminami-ku, Kitakyushu-city Fukuoka, 802-0985, \\ Japan
}

*Corresponding Author. moritsugu@boss.ecs.kyutech.ac.jp

\begin{abstract}
This paper describes the use of capacitor of two pairs as a water level meter. A water level meter of capacity measure a water level of liquid that poured between electrodes. However, this sensor requires you know permittivity of its liquid. We proposed a water level meter of capacity that isn't influenced permittivity of liquid. This sensor that use capacitor of two pairs remove permittivity in formula of water. We demonstrated that we could measure the level of water. These results suggest that this configuration is a promising candidate for use as a water level meter.
\end{abstract}

Keywords: water level meter, capacitor of two pairs, permittivity, dielectric substance

\section{Introduction}

The factories develop by upgrade of production system. In the factories, the global production activities are managed by computers ${ }^{(1)}$.

The sensors are most important in the factory. The factory uses image sensor, pressure sensor, magnetic sensor etc.

The water level meter measure level of water in tank. There are some kinds of water level meters. The water level meter of capacity use variation of capacitance in capacitor. This method has characteristic that is easy maintenance, not choose measuring object and can use on high temperature and high pressure. However, this method necessary knew permittivity of measuring object.

The material has organic permittivity. But, the permittivity change by temperature ${ }^{(2)}$. Therefore, if the materials don't fix and the temperature don't fix, water level meter of capacity can't measure water level ${ }^{(3)}$.
This paper proposes a water level meter of capacity that isn't depended permittivity of measuring object. Our device is more general water level meter of capacity that isn't depended kind of measuring object.

\section{A Water Level Meter of Capacity}

In this section, we will describe structure of a water level meter of capacity.

Firstly, the capacitance of capacitor that not put dielectric substance can be expressed as:

$$
C=\varepsilon_{0} \frac{S}{d}
$$

If we pour dielectric substance of permittivity $\varepsilon_{\mathrm{r}}$ in between electrodes, device's capacitance can be expressed as:

$$
\begin{aligned}
& C=\varepsilon_{0} \frac{S_{1}}{d}+\varepsilon_{0} \varepsilon_{r} \frac{S_{2}}{d} \\
& ※ S=S_{1}+S_{2}
\end{aligned}
$$

where we express area $S_{1}$ that touch air and area S2 that touch dielectric substance. This expression that is transformed can be expressed as:

$$
C=\varepsilon_{0} \frac{S}{d}+\varepsilon_{0}\left(\varepsilon_{r}-1\right) \frac{S_{2}}{d}
$$

We understand capacitance is affected by area $S_{2}$ that touch dielectric substance. Area $S_{2}$ proportionate the water level. As a result, if we calculated area $S_{2}$ by capacitance C, we calculate the water level.

Secondly, we describe formula of water level of conventional model. Figure 1 illustrates the conventional water level meter of capacity. The device's parameter is illustrated Figure 1 . We call the capacitance $\mathrm{C}_{0}$ when measuring object (dielectric substance) isn't put the device. Capacitance $\mathrm{C}_{0}$ can be expressed as: 


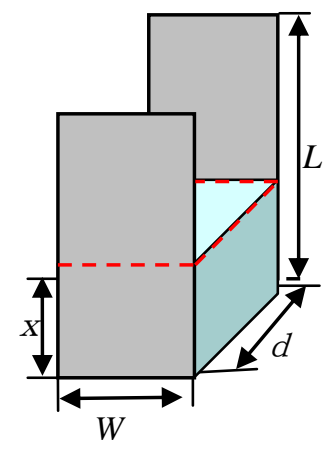

$W$ : width of electrodes

$L$ : height of electrodes

$d$ : distance of electrodes

$x$ : water level

$\varepsilon_{0}$ : permittivity of air $=$ $8.86 \times 10^{-12}$

$\varepsilon_{1}$ : relative permittivity of liquid.

Fig. 1. Conceptual diagram of water level meter of capacity.

$$
C_{0}=\varepsilon_{0} \frac{W L}{d}
$$

We calculate capacitance $\mathrm{C}$ from this formula.

$$
C=C_{0}+\left(\varepsilon_{r}-1\right) \frac{C x}{L}
$$

We calculate water level $\mathrm{x}$ from this formula.

$$
x=\frac{L}{\varepsilon_{r}-1} \times\left(\frac{C}{C_{0}}-1\right)
$$

We understand formula of water level contains dielectric substance of measuring object. If we want the formula of water level that not contains dielectric substance of measuring object, we require the simultaneous equations that obtains similar parameters.

\section{Proposed Approach}

In this section, we describe our method.

The conventional model not builds simultaneous equations of capacitance because it measure water level by one capacitor. Figure 2 illustrates structure of our method. Our method locates the triangular capacitor of two pairs. As a result, each capacitance changes different because each area that touches capacitor is different. In addition, each capacitor has similar parameters. Therefore, we can make simultaneous equations from each capacitance $\mathrm{C}_{1}$ and $\mathrm{C}_{2}$. If we set the variable on water level $\mathrm{x}$ and dielectric substance $\varepsilon_{\mathrm{r}}$, we calculate formula of water level that not contains dielectric substance.

The device's capacitance $\mathrm{C}_{0}$ can be expressed as:

$$
C_{0}=\varepsilon_{0} \frac{W L}{2 d}
$$

when water level $\mathrm{x}=0$. It is similar to $\mathrm{C}_{1}$ and $\mathrm{C}_{2}$. As a result, capacitance $C_{1}$ and capacitance $C_{2}$ can be expressed as:

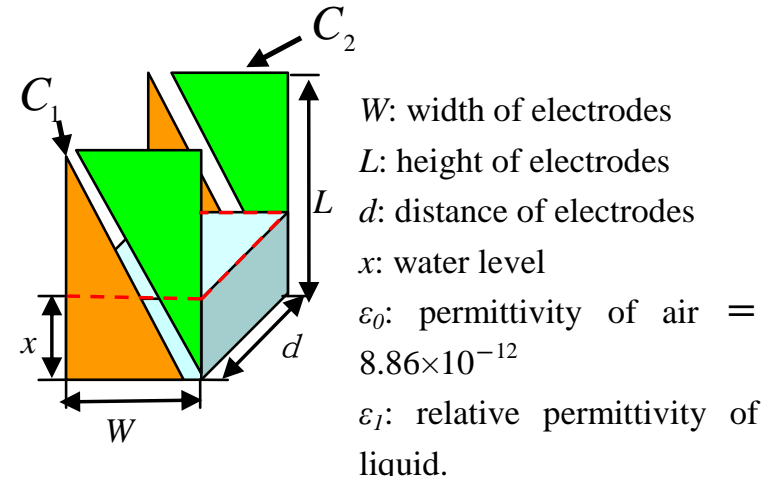

Fig. 2. Conceptual diagram of our method.

$$
\begin{aligned}
& C_{1}=C_{0}\left(1+\left(\varepsilon_{r}-1\right)\left(\frac{2 x}{L}-\frac{x^{2}}{L^{2}}\right)\right) \\
& C_{2}=C_{0}\left(1+\left(\varepsilon_{r}-1\right) \frac{x^{2}}{L^{2}}\right)
\end{aligned}
$$

We solve simultaneous equations.

$$
x=\frac{2 L\left(C_{2}-C_{0}\right)}{C_{1}+C_{2}-2 C_{0}}
$$

A water level $\mathrm{x}$ is expressed (10). We understand if we know device's width $\mathrm{L}$ and capacitance $\mathrm{C}_{0}$, we calculate water level $\mathrm{x}$ from capacitance $\mathrm{C}_{1}$ and capacitance $\mathrm{C}_{2}$.

\section{Construction of Device}

In this section, we describe construction of device.

Figure 3 illustrates size of device. The electrodes of device are actually manufacture trapezoidal shape because capacitance of triangular electrodes changes small. Therefore, our device decreased error of measurement. Each capacitance $\mathrm{C}_{1}$ and $\mathrm{C}_{2}$ can be expressed as:

$$
\begin{aligned}
& C_{1}=C_{0}\left(1+\frac{1}{L}\left(\varepsilon_{r}-1\right)\left(1+\frac{x}{L}\left(\frac{2 x y}{W}-1\right)\right)\right. \\
& C_{2}=C_{0}\left(1+\frac{1}{L}\left(\varepsilon_{r}-1\right)\left(\frac{2 x y}{W}+\frac{1}{L}\left(1-\frac{2 x y}{W}\right)\right)\right.
\end{aligned}
$$

in device. We solve simultaneous equations (11) (12).

$$
\begin{aligned}
& x=\frac{2 L\left(W C_{x}-y\right)}{W-2 y} \\
& ※ C_{x}=\frac{C_{2}-C_{0}}{C_{1}+C_{2}-2 C_{0}}
\end{aligned}
$$

A water level $\mathrm{x}$ is expressed as (13). We input parameter of Figure 3 (width $\mathrm{W}$, height $\mathrm{L}$, distance of between electrodes $d$, top width of trapezoid y) in formula of water level (13).

$$
x=0.333 C_{x}-0.0666
$$




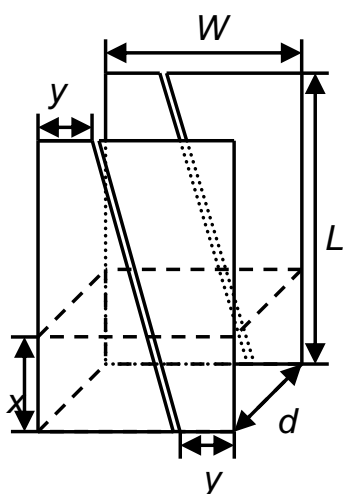

$W: 10(\mathrm{~cm})$

$L: 10(\mathrm{~cm})$

$d: 3.5 \mathrm{~mm}$

L $\quad y: 2(\mathrm{~cm})$

$x$ : water level $(\mathrm{cm})$

$\varepsilon_{0}$ : permittivity of air $=$ $8.86 \times 10^{-12}$

$\varepsilon_{l}$ : relative permittivity of liquid.

Fig. 3. Size of our device

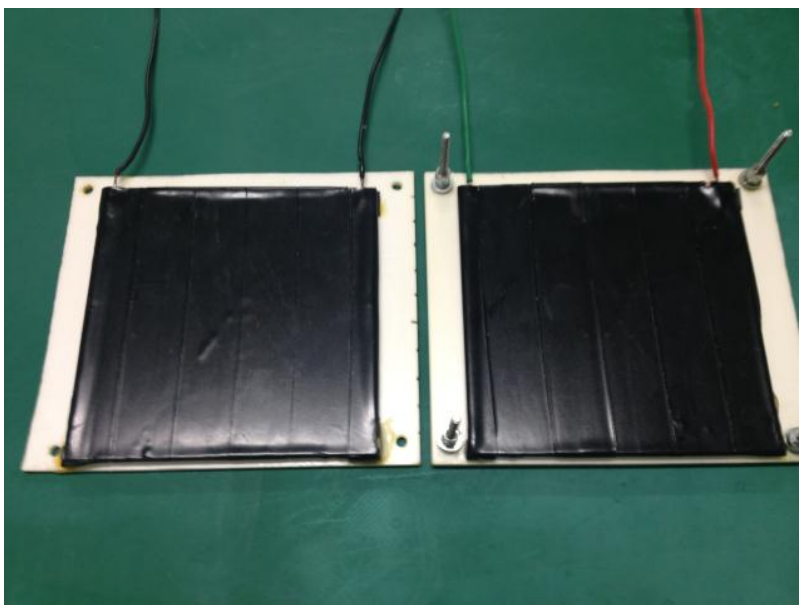

(a) Inside

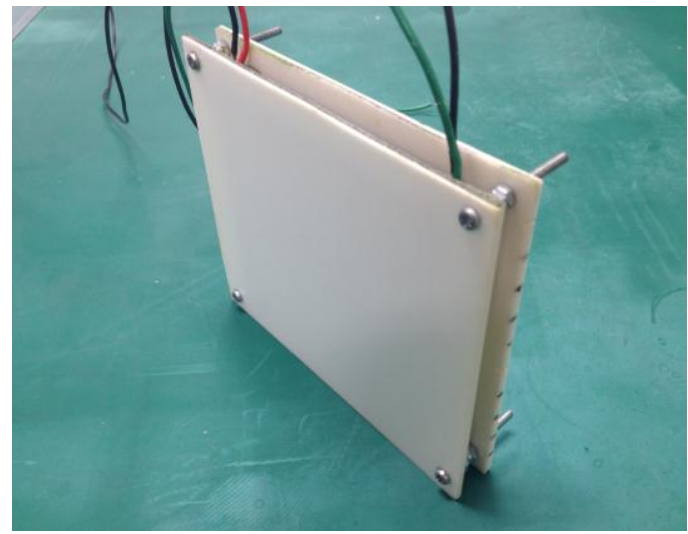

(b) Outside

Fig. 4. Photo of our device.

Formula (14) is formula of water level in our device.

Figure 4 illustrates photo of our device that is actually manufactured.

Figure 4 (a) illustrates inside of our device. We set electrodes of two pairs tat cut boards of copper. In addition, we rolled insulated tapes on face of boards of copper because between electrodes not conduct. Finally, we fixed

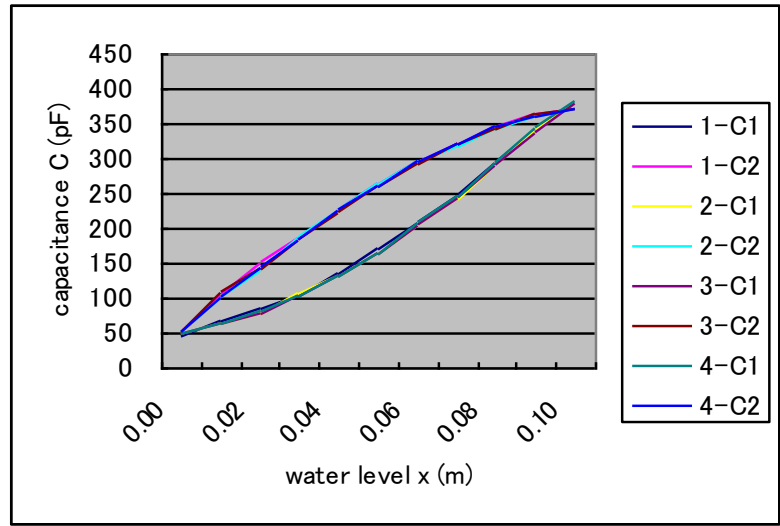

(a) Water

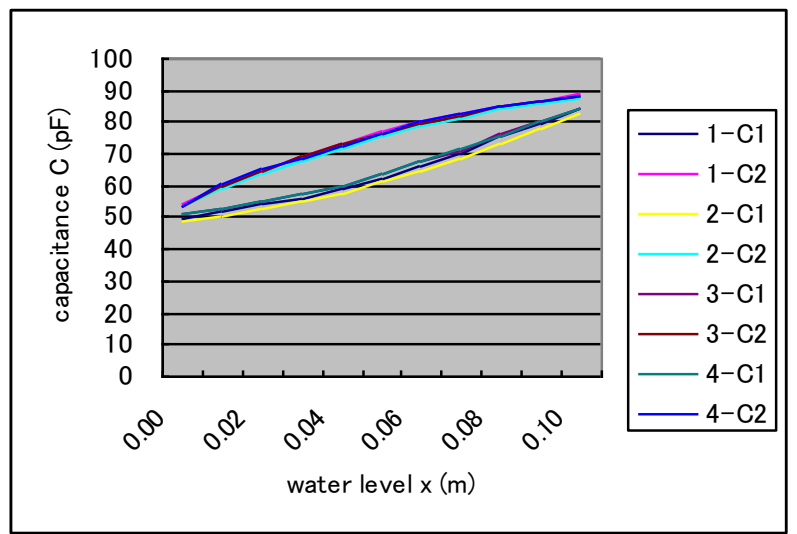

(b) Oil

Fig. 5. Measuring capacitance of both water and oil.

it for plastic boards.

Figure 4 (b) illustrates outside of our device. We fixed plastic boards of two pairs by bolt and screw.

\section{Experimental Method}

In this section, we describe examination on our device.

We test our device that measure water level because we need to verify the performance of our device.

Measuring object is water (Relative permittivity = 80.4 ) and rape seed oil (Relative permittivity $=3.1$ ). We measure the water level of its liquid. In addition, we calculated water level of its liquid.

First, we locate our device in the container. Second, we pour measuring object in the container. In that case, we decide that interval of water level is $1(\mathrm{~cm})$. We measure water level until water level $=10 \mathrm{~cm}$. (Interval of water level $=1 \mathrm{~cm}$, Maximum value of water level $=10 \mathrm{~cm}$ )

Figure 5 (a) and (b) illustrates graph that compare variable of capacitance by water and oil. The variable of capacitance of oil is smaller than water. Therefore, if 


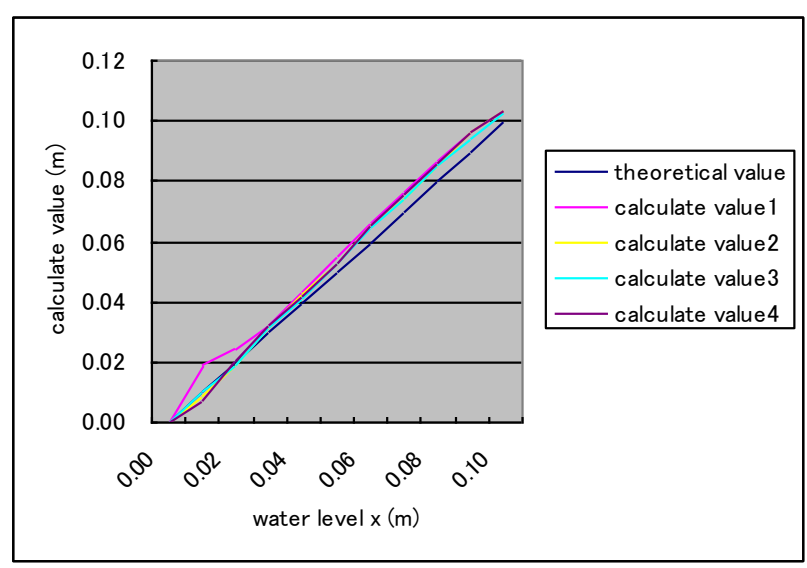

(a) Water

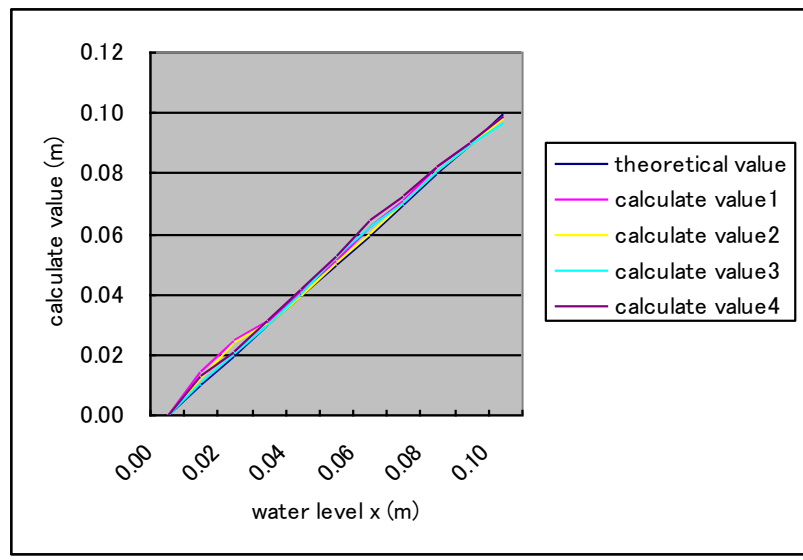

(b) Oil

Fig. 5. Comparison of both calculate value and theoretical value of water level.

relative permittivity is small, the error of water level increases by noises.

Figure 6 (a) and (b) illustrates calculate value and theoretical value of water. Figure 6 (a) illustrates calculate value and theoretical value of water. The calculate value and the theoretical value are even in Figure 6 (a) and Figure 6 (b). We understand our method isn't influenced from noises. As a result, our method certifies that isn't influenced measuring object.

\section{Conclusion}

We measure water level that isn't influenced permittivity of measuring object by our device. As a result, our device is more general water level meter of capacity that isn't depended kind of measuring object.

In the future, we are going to increase the precision of measurement. If measuring assembly is more greatly, we will measure better than now. In addition, we are going to make our device that more compactly. If we manufacture the cylindrical electrodes, our device is more compactly.

\section{References}

(1) Kanda Yuichi : "Manufacturing Systems and Factory Automation", Journal of the Japan Society of Mechanical Engineers, Vol.107, No.1027, pp.454-455, 2004

(2) Kazuo Fujio : "Dielectric Properties of Sea Ice", Low Temperature Science, Series A Physical Science, No.25, pp127-169, 1967

(3) Yokoi Hisayoshi : "The Development of Water Level Meter Used Magnetic Strain Probe for Precision Measurement of Ponding Depth of Paddy Field", Res. Bull. Aichi Agric. Res. Ctr, Vol.42, pp.23-30, 2010 